\title{
Mitos e ritos
}

\author{
Carmen Junqueira
}

\begin{abstract}
Resumo
O texto busca compreender melhor o significado da expressão "tradição", usada com frequência pelos Kamaiurá (MT) e outros povos indígenas do Brasil. Pelo que foi possível constatar, o horizonte da tradição não coincide com o horizonte da cultura como um todo, mas se constitui de um núcleo central que reúne os costumes mais valorizados.
\end{abstract}

Palavras-chave: Tradição. Mudanças culturais. Mito. Kwaryp. Povo Kamaiurá. Alto Xingu.

\begin{abstract}
This text aims to a better understanding of the meaning of the word "tradiction", frequently used (spoken?) by the Kamaiurá (MT) and other native Brazilian. As far as it could be confirmed (verified?), the horizon of tradition does not coincide with the horizon of culture as a whole, but it is made of a central core (nucleus?), which assembles the most valued (appraised?) customs (practices ?).
\end{abstract}

Keywords: Tradition. Cultural changes. Myth. Kwaryp. Kamaiurá people. High Xingu.

É muito comum ouvir representantes de comunidades indígenas almejarem "guardar a tradição", "resgatar a tradição", "salvar a tradição", sem que nunca deixem claro o querem dizer por Tradição. É possível supor que ela faça parte de um fenômeno social maior, a cultura, entendida aqui em sentido lato. ${ }^{1}$ Pode-se ainda inferir que a referida cultura esteja passando por um processo de mudança, que para os membros do grupo poderia parecer ameaçador. Tais suposições ajudam a delinear o contexto em que a tradição se insere, sem contudo defini-la com clareza. Assim, seria útil verificar se cultura e tradição são a mesma coisa, isto é, se o horizonte da cultura coincide com

1 Penso aqui na definição de cultura formulada por Edward B. Tylor:"Cultura e civilização, tomadas em seu sentido etnológico mais vasto, são um conjunto complexo que inclui o conhecimento, as crenças, a arte, a moral, o direito, os costumes e as outras capacidades ou hábitos adquiridos pelo homem enquanto membro da sociedade" (1871:1 apud Cuche 2002). 
o horizonte da tradição. Na Pontifícia Universidade Católica de São Paulo há alguns estudantes indígenas nos cursos de graduação e pós-graduação. Aproveitei o contato com os que cursavam mestrado em Ciências Sociais para perguntar o que entendiam por tradição. A resposta foi invariavelmente a mesma: entendiam por tradição as diferentes cerimônias que envolviam danças, cantos, rituais e os mitos. Apesar de todos esses jovens serem falantes da língua nativa, nenhum mencionou espontaneamente sua própria língua como parte da tradição. Mas quando indagados se ela também fazia parte da tradição foram enfáticos em responder afirmativamente. Aqui já é possível avançar a suspeita de que fenômenos fortemente estabelecidos, como a língua, por serem parte integrante da existência social são de tal modo naturalizados que a ninguém ocorre cita-los como tradição.

Na última viagem que fiz aos Kamaiurá, no alto rio Xingu (MT), em julho de 2011, inclui no roteiro de entrevistas de uma pesquisa sobre percepção das mudanças culturais a pergunta feita aos estudantes da PUC: O que é tradição para os Kamaiurá? Nas oito entrevistas realizadas os informantes responderam que sua tradição reuniaa luta huka-huka, as festas (cerimônias), os cantos, as danças, o toque das diferentes flautas, a reclusão, os remédios extraídos de plantas, a prática da escarificação, as pinturas corporais, o corte do cabelo. $\mathrm{O}$ cacique da aldeia sintetizou sua explicação: "Tradição é o que vocês chamam em português de cultura. A cultura que a gente vem trazendo e levando para o futuro".

Comparando essas respostas com as dos estudantes da PUC constatase maior variedade dos costumes citados, pois sendo a cultura kamaiurá mais preservada bastava aos informantes recolher da experiência vivida os exemplos que mais valorizavam. Mas de modo geral, os dois grupos enfatizam os ritos e os mitos, a narrativas que os ensinam como viver corretamente. Os depoimentos kamaiurá mostram ainda que tradição não inclui relações de trabalho, tecnologia, distribuição, troca e outros fenômenos sociais que fazem parte da cultura. Para eles, as mudanças que resultaram da relação mais estreita com as frentes de expansão econômica e incluem a substituição dos antigos instrumentos de trabalho, a introdução de equipamentos motorizados (motores de popa, caminhão, trator etc.) alteração nas relações políticas internas e externas, entre outras, não ameaçam a tradição. Há sim a percepção de que a escola pode causar mudanças. Mas o mesmo não é verdadeiro em relação a TV, jogo de futebol, visitas às cidades vizinhas. Enfim para os Kamaiurá os costumes cotidianos seguem o ritmo dos tempos, da história e sofrem alterações continuadas. A tradição, que guarda em seu núcleo os mitos e os ritos, permanece e deve ser guardada, relembrada e protegida.

Convém examinar mais detidamente os mitos e os ritos. Rito e mito nem sempre andam juntos, isto é, nem todo mito é rememorado em ritos. É possível 
encontrar narrativas míticas importantes entre os Kamaiurá (p.ex. a obtenção do dia, a criação da lagoa de Ipavu etc.) sem sua dramatização em cerimônias. Por outro lado, é comum o rito estar ligado a um mito ou conhecimento ancestral. Mas o rito também pode ser praticado sem ligação explícita com outras esferas da cultura. O que são mito e rito?

Pode-se definir MITO como uma narrativa que fala de deuses, de heróis culturais, da origem de várias coisas como determinadas festas, ou alimentos, certos animais etc. No linguajar comum, a palavra mito tem vários significados como, por exemplo: uma ideia falsa, uma pretensão inatingível (ele corre atrás do mito do progresso). No campo religioso as narrativas de uma crença religiosa podem ser chamadas de mito por outra religião que se pretende a única verdadeira. Assim a narrativa da criação do mundo para determinada religião é uma revelação, enquanto narrativas de outras religiões são designadas mitos, isto é, falsas, ilusórias. É interessante comparar algumas narrativas míticas sobre a criação:

1. Upanixades, texto filosófico escrito entre os séculos VIII e IV a.C., que foi anexado às escrituras hindus como Vedanta.

[...] este universo não era senão o Si-Próprio na forma de um homem. Ele olhou em volta e viu que não havia nada além de si mesmo, de maneira que seu primeiro grito foi: "Sou Eu", e daí surgiu o conceito "eu" Então, ele teve mede. Mas considerou: "Como não há ninguém aqui além de mim mesmo, o que há para temer?” Em consequência disso o medo desapareceu.

Entretanto, ele carecia de prazer. Ele era exatamente tão grande quanto um homem e uma mulher abraçados. Esse Si-Próprio dividiu-se então em duas partes, e com isso passou a haver um senhor e uma senhora.

O macho abraçou a fêmea e desse abraço surgiu a raça humana. Ela, entretanto, refletiu: "Como ele pode unir-se a mim, que sou produto dele próprio? Bem, então vou esconder-me!” Ela tornou-se uma vaca, ele um touro, e uniu-se a ela, e dessa união surgiu o gado. Ela tornou-se uma égua, ele um garanhão, ela uma jumenta, ele um jumento e uniram-se, e disso surgiram os animais de casco. Ela tornou-se uma cabra, ele um bode: ela uma ovelha, ele um carneiro e uniram-se, e surgiram as cabras e as ovelhas. Dessa maneira ele criou todos os pares de criaturas, até as formigas. E então percebeu: "Na verdade, sou a criação; pois tudo isso brotou de mim. Daí surgiu o conceito de "Criação".

Todo aquele que entender isso torna-se, verdadeiramente, ele próprio um criador nessa criação. ${ }^{2}$

2 Campbell (1994:18). 
2. Livro do Gênesis:

1. No princípio, criou Deus os céus e a terra.

2. A terra, porém estava sem forma e vazia; havia trevas sobre

a face do abismo, e o Espírito de Deus pairava por sobre as águas.

3. Disse Deus: Haja luz; e houve luz.

[...]

20. Disse também Deus: Povoem-se as águas de enxames de seres viventes; e voem as aves sobre a terra, sob o firmamento dos céus.

21. Criou, pois, Deus os grandes animais marinhos e todos os seres viventes que rastejam, os quais povoaram as águas, segundo as suas espécies; e todas as aves, segundo as suas espécies. E viu Deus que isso era bom.

[...]

24. Disse também Deus: Produza a terra seres viventes, conforme a sua espécie: animais domésticos, répteis e animais selváticos, segundo a sua espécie. E assim se fez.

25. E fez Deus os animais selváticos segundo a sua espécie, e os animais domésticos, conforme a sua espécie, e todos os répteis da terra, conforme a sua espécie. E viu Deus que isso era bom. 26. Também disse Deus: Façamos o homem à nossa imagem, conforme a nossa semelhança: tenha ele domínio sobre os peixes do mar, sobre as aves dos céus, sobre os animais domésticos, sobre toda a terra e sobre todos os répteis que rastejam pela terra.

27. Criou Deus, pois, o homem à sua imagem, à imagem de Deus o criou: homem e mulher os criou.

28. E Deus os abençoou e lhes disse: Sede fecundos, multiplicaivos, enchei a terra e sujeitai-a; dominai sobre os peixes do mar, sobre as aves dos céus e sobre todo animal que rasteja pela terra. $^{3}$

3. Narrativa kamaiurá sobre a criação dos homens

No imaginário kamaiurá o mundo sempre existiu. Sempre houve a terra, o céu, as águas, matas e animais das mais diversas variedades. Havia ainda os espíritos (mama'e) donos de várias espécies animais e mesmo vegetais. Somente um homem vivia na terra. Era Mavutsinin. Casou-se ele com a concha e da união nasceu um menino. "É homem ou mulher, perguntou Mavutsinin à esposa, tão logo a criança nasceu?

3 Bíblia Sagrada (1993:3). 
Homem, respondeu ela. Então levo comigo!” A concha em prantos se fechou e voltou às águas.

Contam os mais velhos que o filho recebeu o nome do pai, Mavutsinin. "Ele é filho de Mavutsinin, mas nós dizemos que é neto". Esse foi o modo que os Kamaiurá acharam para não violar a regra vigente na sociedade relativa à transmissão de nomes e que define que o nome o avô (avó) é transmitido para o neto (neta).

Mavutsinin cresceu e resolveu povoar o mundo com seres iguais a ele. Diz a tradição que em tempos recuados, o Kwaryp foi realizado em Morená, terra situada na confluência dos rios Ronuro, Batovi e Culuene, local da morada de Mavutsinin.

Mavutsinin cortou troncos de árvore, fincou-os no chão, pintou-os e finalmente enfeitou-os com colares, braçadeiras de penas de arara, cocares e fios de algodão. Ao som de maracás, duas cutias entoaram cantos que se estenderam por longas horas, até que pouco a pouco os troncos foram ganhando forma: primeiro surgiram os braços, depois a cabeça, o tronco, pernas e enfim todo o corpo.

Mas a criação estava incompleta. Era preciso dar a cada criatura uma identidade própria. Mavutsinin mostrou-lhes vários artefatos para que escolhessem o que mais os agradassem. Os Kamaiurá, convocados em primeiro lugar, escolheram o arco preto, os Kuikuro o colar de lâminas de concha, os Kalapalo o cinto de discos de caramujo, os Waurá a panela de cerâmica, até que todos, embora semelhantes na origem, pudessem ostentar peculiaridades e diferenças. ${ }^{4}$

São três narrativas míticas guardadas em religiões diferentes entre si. O mito indiano mostra que as criaturas são o criador. No mito bíblico o homem é criado à semelhança de Deus. O mito indígena apresenta um deus que é parte da natureza e com elementos da natureza cria o ser humano. O mito indiano assinala a sacralidade dos seres vivos, o mito bíblico enfatiza o homem como conquistador da natureza, enquanto no indígena, o homem é natureza.

Narrativas mitológicas que tratam da origem da vida, do advento da morte e outros episódios marcantes da trajetória humana são guardados como saberes centrais em inúmeras sociedades, sendo transmitidos às novas gerações no processo de socialização. Em sociedades que fazem uso da escrita, essas narrativas são perpetuadas por longa extensão de tempo até que a falta de sintonia entre o conteúdo do texto e as condições concretas da existência social passem a exigir uma interpretação dos eventos constantes da trama original, de modo a torná-los plenamente compreensíveis. Em sociedades de

4 Junqueira e Vitti (2005:133-148). 
tradição oral o mais provável que as narrativas sejam atualizadas pelos próprios narradores com o passar do tempo. Penso que em sociedades indígenas onde é grande o número de mitos, estejamos de fato diante de diversas partes de uns poucos mitos originais. Assim, em épocas recuadas, teria havido grandes textos que com o passar do tempo e o trabalho da memória desdobraram-se em narrativas autônomas e eventualmente se prolongaram em nova direção. Uma leitura atenta do patrimônio mítico de um povo sugere a existência de conexões estreitas entre várias narrativas. ${ }^{5}$ No limite, o impacto de mudanças no modo de vida, geradas pela expansão capitalista, pode ainda reduzir os diferentes episódios desmembrados em simples fragmentos, muitas vezes carentes de sentido explícito. Evidentemente, o caminho menos indicado para compreender esses restos é explica-los avançando hipóteses norteadas pela nossa própria lógica.

Para as Ciências Sociais, o RITO é um tipo de cerimônia na qual determinadas maneiras de agir, palavras, gestos ou símbolos são vistos como dotados de poder para produzir resultados desejados. Todas as sociedades humanas possuem ritos, nas mais variadas esferas da cultura. Nascimento, infância, puberdade, maturidade, velhice e morte são situações determinadas pela biologia e grande parte das sociedades humanas dão destaque a um ou a vários desses momentos, ou mesmo a todos eles. Uma característica interessante dos ritos é dar destaque ao trânsito de uma situação a outra como, por exemplo, a saída da infância em direção à adolescência, fazendo dele um ato cercado de cuidados especiais. Um estudo clássico dedicado ao tema mostra que os diferentes ritos de passagem têm estruturas comuns: contêm um rito de separação, seguido de um rito de margem e um posterior rito de agregação. Esses três momentos não têm sempre o mesmo destaque nos eventos definidos pela biologia (nascimento, morte etc.) ou pela vida social (casamento, maternidade ou paternidade etc.); é comum o rito de separação ser mais elaborado nas cerimônias funerárias; o rito de agregação nos casamentos e o de margem na gravidez. ${ }^{6}$

Ritos de separação são destinados a cortar os vínculos com um estado anterior. Incluem-se aqui ritos relativos ao luto, divórcio, declaração de guerra etc. Na nossa sociedade, por exemplo, por ocasião da morte ocorre o ritual do velório e do sepultamento. Para pessoas religiosas há ainda o ritual da missa. Um aspecto interessante da teoria dos ritos de passagem é o que aponta a existência de um momento de parada, um ponto morto entre as situações contrastantes de separação e agregação. Sua função seria preparar a mudança, instaurando um período de margem, ou período liminar, caracterizado pela suspensão das regras que usualmente regem a vida cotidiana.

5 Junqueira (2009:181-197).

6 Van Gennep (1978). 
Os Kamaiurá marcam de modo bem claro a etapa da vida relativa à entrada na puberdade, isto é a passagem da infância para a vida adulta, com o ritual da reclusão. As moças quando da primeira menstruação ficam reclusas num canto da casa e sujeitas a regras de comportamento e dieta alimentar especiais. A reclusa está deixando de ser criança para se tornar mulher; é separada da condição de criança e será agregada à camada dos adultos.O mesmo ocorre com relação aos meninos quando apresentam sinais de maturidade física. A reclusão prepara meninas e meninos para se formarem células familiares e procriarem.

Ritos de agregação bastante difundidos são as cerimônias que incluem atos de comer e beber em conjunto, como forma de confraternização. Em certas religiões, o batismo é uma forma de agregar o indivíduo à comunidade de fiéis. $\mathrm{O}$ ato de atribuir nome à criança significa agregá-la a determinada família ou sociedade. O casamento é igualmente um ritual de agregação.

Falamos antes do mito e em seguida do rito, mas de fato em muitas ocasiões mito e rito se entrelaçam. Na esfera religiosa isso é comum; basta lembrar a missa cristã, em que momentos de uma narrativa são rememorados ritualmente. Gostaria de mostrar de maneira mais detida o desenrolar de uma importante cerimônia kamaiurá, na qual ocorre a conjunção de vários ritos e mitos com a finalidade de atenuar o sofrimento psicológico causado pela morte.

Vimos anteriormente que o ser humano foi criado por Mavutsinin a partir de troncos de madeira. Pois bem, essa narrativa se prolonga numa outra de categoria semelhante: Mavutsinin viu que as pessoas não tinham vida eterna, como ele próprio. Elas morriam. Isso ocorre, dizem ainda hoje os Kamaiurá, porque a pedra chamou o Kamaiurá, mas ele não respondeu ao chamado; a árvore o chamou e ele, prontamente, respondeu. Por isso morremos.

Ainda naqueles primórdios, Mavutsinin resolveu fazer um Kwaryp, semelhante à cerimônia da criação do ser humano, mas com o objetivo de fazer os mortos reviverem. Antes do início dos procedimentos ele pediu que as portas das casas fossem fechadas. Teve início a cerimônia diante dos troncos de madeira adornados, que aos poucos começaram a ganhar forma humana. "Quando a transformação se completou, Mavutsinin mandou que os homens saíssem das casas para saudar os renascidos, expressando sua alegria. Apenas os que tivessem tido relação sexual na noite anterior não deveriam deixar suas casas para participar da comemoração. Somente um homem permaneceu dentro da casa, mas vencido pela curiosidade, saiu para apreciar o espetáculo. No mesmo instante os ressuscitados voltaram a ser troncos de madeira. Mavutsinin lamentou que seu intento de dar vida aos mortos tivesse sido frustrado pela transgressão ritual e lançou a imprecação: 
De agora em diante, os mortos não conhecerão uma nova vida por ocasião da cerimônia do Kwaryp, nela serão apenas relembrados e homenageados"”.

A cerimônia do Kwaryp realizada regularmente pelos Kamaiurá é uma sequência de etapas rituais destinadas à retirada do luto. Os mitos sobre a criação e a tentativa de dar vida aos mortos, ao lado de outros mitos secundários, levam a comunidade a participar de modo solidário da delicada tarefa de afastar a dor causada pela morte. Parentes ou não da pessoa falecida, todos os moradores reconhecem a dor do outro silenciando a comunidade. Passados alguns dias tem início uma sequência de rituais que organizam os procedimentos da superação da dor dos enlutados.

De modo sintético, são três as fases do Kwaryp:

1. A primeira tem início logo após o falecimento da pessoa e trata especialmente dos cuidados relativos ao corpo do morto e seu sepultamento. Um grupo de homens da aldeia se oferece para cavar a sepultura, banhar, pintar e adornar o morto. As mulheres são enterradas junto com seu fuso de fiar e os homens, com arco e flechas. O corpo é coberto com esteiras, envolto na rede de dormir, que é então costurada. Após o enterramento, no pátio da aldeia, os enlutados mais próximos do morto, recebem um banho ritual sobre a sepultura para lavar as lágrimas. Durante 3 dias os enlutados fazem uma fogueira sobre a sepultura para ajudar a alma a encontrar o caminho para a aldeia das almas, pois ela insiste em permanecer na casa onde sempre morou. Após alguns dias o luto da aldeia é aliviado. Passadas duas semanas o líder dos homens que enterraram o morto consulta os enlutados para saber se podem fazer uma pescaria; a família enlutada concorda e reúne forças para levantar jiraus e coletar lenha para assar os peixes que serão distribuídos a todos da aldeia. Nessa ocasião ocorre o corte do cabelo do enlutados e o banho ritual. Finda a cerimônia, todos da comunidade são banhados sobre a sepultura. Esses rituais ajudam os enlutados a expressar sua dor e também aliviam a aflição momentânea causada pelo impacto da morte.

2. A segunda etapa ocorre várias semanas após a morte, quando os enlutados são instados a definir se desejam ou não o prosseguimento dos rituais. A decisão tem como ponto central a construção de uma cerca baixa de madeira (apenap) ao redor da sepultura e o consentimento significa que os enlutados concordam com a futura realização da cerimônia final do Kwaryp. Membros da aldeia saem para o corte da madeira para fazer o cercado da sepultura. Ao final da fixação das pequenas toras de madeira ocorre a apresentação de dois cantores que entoam cantos rituais junto á sepultura. Em seguida os homens da aldeia, bastante adornados se exibem em uma

7 Junqueira e Vitti (op.cit: 133-134). 
dança denominada morahai, no pátio central. Findo a cerimônia, há distribuição de alimentos a todos, fornecidos pela família enlutada.

3. A terceira e última etapa tem início quando as Plêiades podem ser vistas na linha do horizonte, anunciando tempo seco, dias quentes, noites frescas e águas propícias à pesca. Em algum momento dos meses de julho, agosto ou setembro intensificam-se os preparativos para a grande festa final do Kwaryp. Após a definição do dia da festa ocorre o corte dos troncos de madeira que irão representar os mortos a serem homenageados ${ }^{8}$. O apenap é retirado do pátio e diante da sepultura os cantadores entoam cantos sendo alternados pela dança morahai executada pelos homens da aldeia. Em seguida é organizada uma grande pescaria que conta com a presença de vários pajés que executarão uma série de rituais para assegurar abundância de peixe. Quando do retorno dos pescadores, os enlutados recebem o banho destinado a tirar o luto. Mensageiros partem levando o convite para as aldeias amigas participarem da grande festa. Os troncos de madeira são fixados no pátio, pintados e adornados. Repetem-se cantos rituais e os toques das flautas uruá. Os enlutados, já pintados, cercam o tronco que representa seu morto em meio a choros e lamentos que varam a noite. No dia seguinte começam a chegar os convidados que acampam nas cercanias da aldeia, conduzidos pelos mensageiros que lhes levou o convite. À noite os lutadores kamaiurá executam a dança do ho'at. Em seguida, adentram o pátio chefes e lutadores de cada aldeia convidada e executam o ho'at e pegam achas da lenha que alimenta as fogueiras colocadas diante dos troncos do kwaryp, levando-as para seu acampamento. Alternam-se cantos rituais e as idas e vindas dos mensageiros que levam peixe e beiju para os acampamentos. Ao amanhecer, os convidados são levados ao pátio da aldeia onde ocorrerá a competição da luta huka-huka. O dono da festa, representando a família enlutada, chama os lutadores kamaiurá, em seguida o chefe de uma das aldeias convidadas chama igualmente seus lutadores. De início são convocados os grandes lutadores e na sequência outros lutadores mais jovens. No final até meninos lutam no pátio. A cerimônia alcança o fim quando visitantes e kamaiurá se exibem tocando as flautas uruá. Castanha de pequi é distribuída aos chefes das aldeias convidadas, por uma jovem saída da reclusão pubertária. Na sequência, os visitantes retornam para suas aldeias de origem.

8 O Kwaryp é realizado quando do falecimento de pessoas da camada mais alta da comunidade: homens morerekwate mulheres nuitu, descendentes dos seres criados por Mavutsinin. As pessoas comuns (kamara) são convidadas pela família que promove a cerimônia a homenagear também seus mortos e colaboram nos preparativos da festa. 
Desde o início do ciclo do kwaryp vários mitos intervém para nortear os procedimentos e vários rituais são realizados para, aos poucos, tornar a dor dos enlutados mais suportável e ser finalmente superada. As narrativas míticas, ao lado da riqueza estética, têm várias outras qualidades: levam à reflexão de questões importantes, tornando-as inteligíveis: a mortalidade humana, a vida após a morte que inclui batalhas com os pássaros por ocasião de eclipse lunar e indicam a importância de munir os mortos de arco, flechas e fusos para tecer armadilhas e muitas outras. Ao permitir o acesso às origens, os mitos ajudam a situar a sociedade kamaiurá num lugar definido na constelação de comunidades humanas. Ao lado dos mitos estão os ritos que se revelam através de ações, gestos e cantos. O mito pede ouvintes, o rito, protagonistas. $\mathrm{O}$ rito é ação, invocação cercada de simbolismo. O mito pode ser colocado no mesmo patamar da criação literária da sociedade não indígena e o rito é também arte: arte do movimento, dos gestos, das vozes. Ambos poderiam ainda ser pensados como evocação da primeira palavra e do primeiro gesto que tornaram nossa espécie essencialmente humana.

\section{Referências}

Bíblia Sagrada. 1993. Tradução de João Ferreira de Almeida. Revista e atualizada no Brasil. 2.ed. São Paulo: Sociedade Bíblica do Brasil.

Campbell, Joseph. 1994. As Máscaras de Deus. Mitologia Oriental. Tradução de Carmen Fischer. São Paulo: Palas Athena.

Cuche, Denys. 2002. A noção de cultura nas ciências sociais. 2.ed. Tradução Viviane Ribeiro. Bauru, SP: EDUSC.

Junqueira, Carmen e Vaneska Taciana Vitti. 2009. O Kwaryp kamaiurá na aldeia de Ipavu. Estudos Avançados 23, 65. São Paulo, Universidade de São Paulo, Instituto de Estudos Avançados.

Junqueira, Carmen. 2009. Mitos Kamaiurá, In: Eugênia Paredes e Denise Jodelet (Orgs.). Pensamento mítico e representações sociais. Cuiabá: EdUFMT/FAPEMAT/ EdIUNI.

Van Gennep, Arnol. 1978. Os ritos de passagem. Petrópolis, RJ: Vozes. 